\title{
DESIGUALDADES NO ACESSO E USO DA INTERNET POR CRIANÇAS E DIREITO FUNDAMENTAL À EDUCAÇÃO NA PANDEMIA COVID-19
}

\author{
Sônia Maria Cardozo dos Santos ${ }^{1}$ \\ Thaís Janaina Wenczenovicz ${ }^{2}$
}

\section{RESUMO:}

Este artigo objetiva analisar o direito ao acesso e ao uso da internet por crianças em cotejo com o direito fundamental à educação, diante da desigualdade social em tempos da pandemia covid-19. Além de proteger as crianças no uso da internet, é necessário garantir acesso a ela. Justifica-se este estudo pela importância do reconhecimento da indivisibilidade e interdependência entre os direitos humanos. Com a pandemia, acentuou-se a necessidade do uso da internet para efetivação do direito fundamental à educação, bem como de vários outros direitos. Utiliza-se procedimento metodológico bibliográfico-investigativo, buscando-se dados estatísticos oficiais.

PALAVRAS-CHAVE: Direito De Acesso À Internet, Crianças, Covid-19, Desigualdade Social, Direito Fundamental À Educação.

\section{INEQUALITIES IN CHILDREN'S ACCESS AND USE OF THE INTERNET AND FUNDAMENTAL RIGHT TO EDUCATION IN COVID-19 PANDEMIC}

\begin{abstract}
:
This article aims to analyze the right to access and use of the internet by children compared to the fundamental right to education, because of social inequality in covid-19 pandemic times. Besides protecting children when using the internet, it is necessary to ensure access to it. This study is justified by the importance of recognizing the indivisibility and interdependence among human rights. With the pandemic, the need for the use of the internet for the realization of the fundamental right to education, along with several other rights, was emphasized. A bibliographic-investigative methodological procedure is used seeking official statistical data.
\end{abstract}

KEYWORDS: right to access the internet, children, covid-19, social inequality, fundamental right to education.

\footnotetext{
${ }^{1}$ Doutoranda em Direito, Programa de Pós Graduação em Direito - PPGD/Unoesc. Servidora pública estadual no Tribunal de Justiça de Santa Catarina (TJSC), Videira. Pesquisadora do Grupo de Estudos e Pesquisas em Interculturalidade, Identidade de Gênero e Personalidade, na Linha de Pesquisa Cidadania e Direitos Humanos: perspectivas decoloniais.

${ }^{2}$ Universidade Estadual do Rio Grande do Sul/UERGS. Docente adjunta/pesquisador sênior. Professora Titular no Programa de Pós-Graduação em Educação/UERGS. Docente/pesquisadora no Programa de Pós-Graduação Stricto Sensu em Direito/Unoesc e coordenadora do Grupo de Estudos e Pesquisas em Interculturalidade, Identidade de Gênero e Personalidade da Linha de Pesquisa Cidadania e Direitos Humanos: perspectivas decoloniais. Professora colaboradora no Programa de Pós-Graduação Stricto Sensu em Educação da Universidade Estadual do Paraná (Unioeste). Avaliadora do INEP - BNI ENADE/MEC. Erechim
} 


\section{INTRODUÇÃO}

O Brasil apresenta desigualdades sociais, econômicas, educacionais, culturais e políticas que se tornaram mais visíveis com a pandemia do novo coronavírus (Sars-CoV-2), causador da Covid-19. Esse vírus infectou cerca de 10 milhões de brasileiros e trouxe à tona muitas violações de direitos fundamentais, principalmente para as pessoas vulnerabilizadas que tiveram maior mortalidade, resultado da desassistência do Estado como a falta de água potável na residência, más condições de acesso à saúde, ausência de saneamento básico e moradias precárias com aglomeração de construções, dentre outros.

As disparidades no País acontecem também no campo da educação e com elementos diferenciados de uma região para outra. Na região Norte apenas 19\% das escolas públicas do Amazonas têm acesso ao abastecimento de água, ao passo que a média nacional é de $68 \%$. Em relação ao esgotamento sanitário, a situação é crítica, pois no Acre, por exemplo, apenas 9\% das escolas públicas têm acesso à rede pública de esgoto; em Rondônia, 6\%; no Amapá, somente 5\% (ONU BRASIL, 2020). Diante desse contexto de desigualdade e de falta da mínima estrutura nas escolas, dentre outros fatores, tornou-se imperiosa a suspensão das aulas.

Antes da Covid-19, professores, legisladores, famílias e outros atores refletiam sobre a pertinência ou não da interação entre educação e internet ou, ainda, de que forma isso poderia ocorrer. Por muito tempo realizaram-se questionamentos sobre o impacto das tecnologias no processo de ensino-aprendizagem. Com a pandemia acentuou-se a necessidade do uso internet para a continuidade dos estudos, trabalho, lazer, comunicação. A adoção das tecnologias de informação e comunicação (TIC) tornou-se indispensável para a educação diante da suspensão das aulas e tornou praticamente imprescindível o acesso a dispositivos como computadores e celulares, bem como o acesso a uma conexão de internet de qualidade.

A presente reflexão tem como objetivo analisar o direito ao acesso e ao uso da internet por crianças em cotejo com o direito fundamental à educação, diante da desigualdade social em tempos da pandemia Covid-19. Para a consecução desses objetivos, utiliza-se do procedimento metodológico bibliográfico-investigativo, buscando-se, dentre outros, dados estatísticos oficiais.

O tema abordado é o direito ao acesso e uso da internet em cotejo com o direito fundamental à educação. A delimitação da temática é sobre esses direitos elencados para 
crianças brasileiras em tempos de Covid-19. Justifica-se este estudo em virtude da importância desses direitos e do reconhecimento de que há indivisibilidade e interdependência entre eles.

$\mathrm{O}$ artigo divide-se em três partes e utiliza-se do procedimento metodológico bibliográfico-investigativo. A primeira parte aborda questões relacionadas à infância e as tecnologias. A segunda parte discorre sobre as tecnologias em tempos de pandemia no contexto educativo. A última e a terceira partes trazem elementos do ideário do colonialismo, das colonialidades e sua incidência sobre a educação.

\section{INFÂNCIA E TECNOLOGIAS}

Em muitas épocas, na história mundial, as crianças não eram consideradas e respeitadas em sua individualidade e condições de desenvolvimento. Não havia um conceito de infância e, nas diversas áreas da vida, os infantes eram tidos como um adulto em tamanho menor. A arte é um exemplo disso, em que as crianças não eram retratadas como crianças, e o vestuário era inapropriado para a idade.

Segundo Ariès (1981, p. 3) a sociedade via mal a criança, e pior ainda o adolescente. A duração da infância era reduzida a seu período mais frágil, enquanto o filhote do homem ainda não conseguia bastar-se. Rapidamente a criança era inserida ao mundo adulto e consequentemente adultizada. Essa simplesmente reproduzia adultos em tamanho menor.

Segundo Silva S. (2017), a adultização, forma de reduzir a fase da infância e adolescência, e a erotização infantil, tornaram-se compreendidas socialmente desencadeando um senso crítico para compreender que algumas questões sociais não deveriam ser submetidas às crianças. Além disso, destacaram-se algumas maneiras adultizantes em que crianças passaram a se tornar pequenos adultos, incluindo vestimentas, forma de se portar e consumir.

As situações descritas pelo historiador francês Ariès ocorreram há muitos séculos, porém, há que se questionar se há, na atualidade, alguma similitude com o tratamento dado para a infância, quando são vinculadas mensagens na internet. Quando as mensagens nas mídias digitais são dirigidas de maneira indistinta, como se todo o público fosse adulto, estão sendo desconsiderados milhões de crianças que diariamente estão conectadas à rede. Muitas vezes, incorre-se em semelhante situação de séculos passados em que as crianças são tratadas como se fossem adultos. 
Livingstone, Carr e Byrne (2015) relatam que de cada três pessoas que acessam a internet, uma é criança, e argumentam contra uma abordagem genérica em relação à idade dos usuários da internet, pois as crianças têm necessidades e direitos específicos que não são atendidos por regimes de governança projetados para "todos". Chamam a atenção da tenra idade da entrada dos infantes na rede, citando o Reino Unido, em que pesquisas dão conta de que $11 \%$ das crianças entre três e quatro anos de idade já são usuários da internet.

A criança encontra-se em situação de maior vulnerabilidade e está sujeita a várias violações de direitos com crimes cibernéticos como pornografia infantil, cyberbullying, tráfico de pessoas (sexual ou para o trabalho), adoção irregular,racismo, crime contra a honra, dano moral, dentre outros. No Brasil, mesmo antes dapandemia da Covid-19, muitas crianças e adolescentes já faziam uso da internet.

No mundo há entidades internacionais, nacionais e governos que agem em prolda internet segura e para coibir a prática de crimes. No Brasil, atuam associações derivadas de internacionais, como Childhood Brasil, SaferNet Brasil, e também entidades de iniciativa nacional. Essas instituições trabalham com prevenção e produzem estatísticas para orientar ações protetivas para as crianças. "De acordo com a SaferNet, nos últimos 14 anos foram contabilizadas mais de 4,1 milhões de denúncias anônimas envolvendo 790 mil páginas (URLs) de pornografia infantil no mundo.” (BRASIL, 2020, p. 9).

No Brasil, anteriormente à pandemia da Covid-19, o foco da utilização da internet por crianças e adolescentes estava centrado na privacidade e prevenção de crimes virtuais praticados contra os infantes, diante de sua vulnerabilidade. Poderes Executivo, Judiciário, Legislativo e os Ministérios Públicos atuavam na prevenção de crimes de pornografia, cyberbullying, tráfico de pessoas para exploração sexual, mas a discussão sobre o direito ao acesso à internet era menos enfatizada.

Antes de 2020, existiam muitos questionamentos quanto à utilização ou não dainternet na educação e de que forma isso poderia acontecer. Em muitos locais, havia (e ainda há) a proibição do uso do celular em sala de aula, tanto por regimentos escolares quanto por leis estaduais, como a Lei n. 4.131 de 02/05/08, do Distrito Federal, e a Lei n. 14.363 de 25/01/08, de Santa Catarina, sob a alegação de que muitos alunos poderiam se distrair ou fraudar as avaliações.

Segundo Livingstone, Carr e Byrne (2015), a política e a governança devem, não só de forma genérica, garantir os direitos das crianças de acessar e usar a mídia digital, levando 
em consideração como a implantação da internet pela sociedade em geral pode melhorar os direitos dos infantes em todos os aspectos.

Os autores enfatizam que a Governança da Internet tinha o foco de evitar o abuso infantil, afastando a criança de materiais ou de práticas sexuais criminosas que a focalizam como vítima. Isso é importante, mas não se pode descuidar da agência do infante, bem como os seus direitos de acesso à internet, à informação, à participação e ao respeito à sua privacidade.

Em relação ao acesso e ao uso da internet para crianças, família, estados e empresas têm a desafiante tarefa de encontrar um equilíbrio entre oportunidades e riscos e de conjugar a liberdade de expressão com o direito à privacidade, para que excessiva proteção não resulte em violação de direitos. É necessária a atuação do Estado diante das vulnerabilidades das crianças usuárias da internet, que nem semprepodem contar com a disponibilidade de tempo ou recursos da família para auxiliá-lase protegê-las. Livingstone, Carr e Byrne (2015) afirmam que é provável que essas dificuldades sejam ainda maiores nos países em desenvolvimento, nos quais não há alinhamento entre os sistemas social, policial e educacional existentes.

Em muitos países e regiões do mundo, além das fragilidades quanto ao uso dainternet, as crianças são submetidas a desigualdades socioeconômicas e violações de muitos direitos. Apesar da ampla adesão à Convenção sobre os Direitos da Criança, ratificada por 196 países (UNICEF BRASIL, 1989), há persistência da pobreza e da desigualdade social para muitas pessoas no mundo, inclusive crianças. Dos 1,3 bilhões de pessoas pobres, cerca de 663 milhões são crianças menores de 18 anos. Cerca de um terço, equivalente a 428 milhões, tem menos de 10 anos (ONU NEWS, 2019).

A Organização das Nações Unidas para a Alimentação e a Agricultura (FAO) alerta que os cerca de seis milhões de crianças com menos de cinco anos que morremanualmente em consequência da fome, são vítimas da fome crônica e da desnutrição (FAO, 2002). Muitas crianças, apesar de não irem a óbito, têm reflexos negativos no seu desenvolvimento. Segundo o relatório da Segurança Alimentar e Nutricional no Mundo (SOFI) de 2019, 4,8 milhões sofrem atraso no crescimento ou desnutrição crônica (9\%) e 700 mil sofrem desnutrição aguda $(1,3 \%)$ (FAO, 2019).

A pobreza e a desigualdade social atingem vários direitos, dificultam ou impedem o acesso e uso da internet, que por sua vez traz vários desdobramentos nodireito fundamental à educação, especialmente visibilizados na pandemia de Covid-19. Os direitos humanos são 
interdependentes, inter-relacionados e indivisíveis segundo a Conferência de Direitos Humanos em Teerã (1968), que foi confirmada no art. $5^{\circ}$ da Declaração e Programa de Ação de Viena, Conferência Mundial sobre Direitos Humanos (ONU, 1993).

As desigualdades não ocorrem somente entre indivíduos. Para Castells (2001, p. 265266), a difusão da internet na maioria dos países está criando uma profunda divisão digital; os centros urbanos e grupos sociais mais educados foram incluídos nas redes, mas muitas regiões e pessoas são descartadas.

\section{TECNOLOGIAS EM TEMPO DE PANDEMIA E O CONTEXTO EDUCACIONAL}

A disseminação da Covid-19 trouxe ainda mais obstáculos para a efetivação do direito à educação em grande parte do mundo. A Organização das Nações Unidas para a Educação, a Ciência e a Cultura (Unesco) realizou pesquisa quantificando os alunos afetados total e parcialmente e estimou que em abril de 2020 quase $90 \%$ dos alunos do mundo não estavam possibilitados de prosseguir com seus estudos (UNESCO, 2020).

O Comitê Gestor da Internet (CGI) no Brasil destaca que com a pandemia da Covid19, nos mais diversos países, tornou-se necessário o uso de tecnologias digitais para realizar "práticas cotidianas de educação, cultura e interação social." Isso visibilizou desigualdades significantes quanto ao acesso e uso da Internet: "Ficou evidente um grave desafio para o acesso à educação remota, o que atingiu a maioria das crianças e dos adolescentes, mas teve um impacto maior entre aqueles mais vulneráveis socioeconomicamente.” (CGI, 2020, p. 60).

Pesquisa realizada antes da pandemia, verificou que 16,5 milhões de crianças e adolescentes de 9 a 17 anos viviam em domicílios com condições limitadas de acesso à internet, estando sem nenhuma conexão com velocidades de download abaixo de 4 Mbps (CGI, 2020).

A história da educação brasileira é marcada por demandas geralmente impulsionadas pela desigualdade, em um contexto em que a educação era destinadasomente para a elite. A exemplo, cita-se a luta pela universalização do ensino público e gratuito. Durante décadas, milhares de crianças brasileiras foram impedidas de efetivar seu direito de frequentar a escola básica. Dentre os inúmeros problemas pode-se citar o analfabetismo como um marcador de exclusão que acompanha a trajetória histórica da educação brasileira até o século XXI. 
De acordo com o Instituto Brasileiro de Geografia e Estatística (IBGE), em 2018, havia 11,3 milhões de pessoas analfabetas com 15 anos ou mais de idade. Já a taxa do "analfabetismo absoluto" no Brasil é de 6,8\% (2020) e segundo os dados internacionais, o analfabetismo não atinge a todos da mesma forma. $\mathrm{Na}$ análise por cor ou raça, em 2018, 3,9\% das pessoas de 15 anos ou mais - de cor branca - eram analfabetas, percentual que se eleva para $9,1 \%$ entre pessoas de cor preta ou parda. No grupo etário 60 anos ou mais, a taxa de analfabetismo das pessoas de cor branca alcança 10,3\% e, entre as pessoas pretas ou pardas, amplia-se para 27,5\%”. (IBGE, 2019a).

A Pesquisa Nacional por Amostra de Domicílios Contínua (IBGE, 2019a) verificou, com relação à cor ou raça, que 55,8\% dos brancos completaram, pelo menos, o ciclo básico; esse percentual entre pretos ou pardos foi de 40,3\%. No Brasil, há uma maior dificuldade para as pessoas de baixa renda efetivarem seus direitos, e essa dificuldade é ainda mais acentuada pela desigualdade racial que penaliza pretos, pardos e indígenas. Segundo o IBGE (2019), o analfabetismo de negros e pardos é mais que o dobro que de brancos.

Com a pandemia faz-se necessário o acesso à internet pelas crianças e adolescentes, mas nem todos estão incluídos digitalmente. Pesquisas revelam que nos domicílios que têm serviços da rede, há preponderância do uso do celular como equipamento para acessar a internet, em 99,2\% das residências; em 48,1\% delas usa- se o computador. As plataformas educacionais proporcionam melhor interatividade quando acessadas por computadores (AGÊNCIA IBGE, 2020).

A obtenção de dispositivos e de conexão de internet de boa qualidade vincula- se, geralmente, aos rendimentos das famílias. O CGI no Brasil verificou que entre os mais ricos, classes A e B, 96,5\% das casas têm conexão de internet; porém nas classes D e E, 59\% não consegue utilizar a rede. Ainda, entre a população com renda familiar inferior a um salário mínimo, 78\% das pessoas com acesso à internet usam somente o celular (CGI, 2020).

Outros dados compilados pelo MEC a ser considerado quando se analisa acesso e permanência na escola a fins de garantir acesso ao direito fundamental social à educação são os resultados do Programa Internacional de Avaliação dos Estudantes, mais conhecido pela sigla Pisa, que em inglês significa Programme for International Student Assessment. Conforme a avaliação, o Brasil ficou em 59 lugar em leitura num ranking de 70 países.

(2020, p. 89) afirmam que "possibilitar o exercício do direito à educação é muito mais que garantir o acesso à mesma, é também propiciar condições de ensino e aprendizagem 
com qualidade.” As crianças e adolescentes necessitam de adequados meios, ou seja, o acesso à internet é imprescindível para a efetivação do direito à educação.

\section{PENSAR A EDUCAÇÃO ALÉM DA IGUALDADE: REFLEXÕES PONTUAIS}

Comumente quando se aloca o termo direito à educação, aproxima-se o conceito de igualdade. Insta assinalar que em uma sociedade em que a desigualdade é uma constância há que se refletir além da dinâmica universalista, tornando-se necessário aproximar a questão da equidade. Pensar a equidade na educação aduz refletir sobre as desigualdades estruturais e simbólicas vivenciadas na educação brasileira há décadas. Ou seja, a equidade em educação é impulsionadora de equidade social e da cidadania, já que o insucesso escolar e o abandono aumentam os riscos de desemprego, de delinquência juvenil e das violências. Nesse aspecto a Comissão Europeia, em 2006, colocou a equidade na agenda das políticas públicas, apresentando ao Conselho Europeu e ao Parlamento uma comunicação sob o título Efficiency and equity in European education and training systems (CEC, 2006).

O Brasil se destaca como uma das maiores sociedades multirraciais do mundo e abriga um contingente significativo de descendentes de africanos dispersos na diáspora. De acordo com o censo 2000, o país conta com um total de 170 milhões de habitantes. Desses, 91 milhões de brasileiros se autoclassificam como brancos $(53,7 \%) ; 10$ milhões, como pretos (6,2\%); 65 milhões, como pardos (38,4\%); 761 mil, como amarelos $(0,4 \%)$, e 734 mil, como indígenas (0,4\%) (IBGE, 2000). Em 2019, do total da população brasileira, a soma dos que autodeclararam-se pretos e pardos foi de 56,2\%, o percentual de brancos, $42,7 \%$ e de indígenas, 1,1\% (IBGE, 2019b).

No tocante à equidade, pode-se identificar historicamente três fases nas políticas públicas de educação, começando com a igualdade de acesso, ou seja, o direito de todos à frequência da escola independentemente da sua origem, passando depois à igualdade de tratamento (ou de recursos), ou seja, a prestação a todos de igual serviço educativo, e mais recentemente à igualdade de resultados e competências (DEMEUSE; BAYE, 2008).

Por outro lado, as inúmeras variáveis dos sistemas escolares que podem interagir no respeitante à equidade colocam também problemas à estabilidade da definição, podendo referir-se o acesso a cada nível do sistema escolar, a atribuição de recursos (professores, material pedagógico, tempo de ensino etc.), as condições de aprendizagem (níveis de inclusão 
ou segregação, currículo, práticas de ensino etc.) e os resultados (taxas de abandono, repetência, transição, competências adquiridas etc.), quer externos (efeitos econômicos e sociais, como o rendimento privado e público) (HERBAUT, 2011).

Existem diversas variáveis e indicadores utilizados no estudo da equidade e da eficiência da educação. Mas os resultados escolares são, em tais estudos, uma variável central, quer seja usada como variável dependente quer como independente, e quer a relação procurada seja com condições sociais ou organizacionais relativas a acesso, participação, recursos ou processo de ensino, quer seja com efeitos sociais e econômicos da educação (HERBAUT, 2011).

A equidade na educação, nos termos acima mencionados, não é um resultado fácil de ser alcançado. Nos anos 60, a Sociologia da Educação demonstrou que há correlação entre o nível socioeconômico das famílias e o desempenho acadêmico dos alunos (BOURDIEU; PASSERON, 1975).

O PAIC3 tem conseguido contribuir para a ampliação da equidade nos anos iniciais do ensino fundamental, diminuindo a distância no desempenho dos alunos que vivem em localidades menos e mais pobres (PADILHA et al., 2013) ou que são de escolas com mais e menos famílias com menor nível socioeconômico (KASMIRSKI; GUSMÃO; RIBEIRO, 2017).

A partir disso, pode-se compreender que o princípio da equidade exige o reconhecimento das desigualdades existentes entre os indivíduos para assegurar a busca pela igualdade. Há, então, uma necessidade de conferir a determinados grupos uma proteção especial e particular em face de sua própria vulnerabilidade (RIBEIRO, 2014, p. 1008).

$\mathrm{O}$ conceito de equidade, aqui apresentado, parte do entendimento de que a distribuição dos bens públicos educacionais deveriam favorecer a população mais vulnerável (DUBET, 2009) e promover a justiça social. A equidade "supõe um princípio capaz de corrigir desigualdades em favor de quem tem menos na distribuição dos bens sociais" (RIBEIRO, 2014, p. 1102).

Considerando esses autores, o conceito de equidade utilizado neste texto, enquanto princípio de justiça, prevê que uma política educacional deveria promover níveis adequados de desempenho a todas as crianças, com destaque para aquelas que possuem menor nível

\footnotetext{
${ }^{3}$ Programa de Alfabetização na Idade Certa: consiste basicamente em um esforço conjunto do Estadoe dos Municípios, no sentido de providenciar a alfabetização de todas as crianças na idade certa, evitando a alfabetização tardia.
} 
socioeconômico. Desde então, as pesquisas, mesmo aquelas que apontam outros fatores intervenientes no desempenho dos alunos, não deixaram de reconhecer o nível socioeconômico como o mais forte preditor da desigualdade escolar (BROOKE; SOARES, 2008).

As discriminações (gênero, orientação sexual, raça, etnia e outras) atreladas à falta de oportunidades são a tradução da complexa realidade em diversos países, e compõem um círculo vicioso de exclusão social. Neste cenário surgem as chamadas ações afirmativas: medidas políticas que visam acabar com a exclusão social, cultural e econômica de indivíduos pertencentes a grupos que sofrem qualquer tipo de discriminação. Essas medidas se baseiam na igualdade (pois possuem respaldo nas leis) e de forma compensatória, asseguram a equidade ao estimularem a inserção, inclusão e participação política dos grupos sociais vulneráveis nos espaços sociais por meio de diferentes auxílios.

Desta forma, as políticas de cunho equitativo são uma forma de garantir a inclusão e inserção ao assegurarem o direito à igualdade e o direito à diferença por meio de ações afirmativas (LIMAS; RODRÍGUEZ, 2008). Ou seja, há que se reconhecer que o acesso e a permanência de milhões de brasileiros à educação perpassam pelo processo de desenvolvimento social da nação.

O Brasil nunca se desvencilhou do dependentismo assentado no ideário do colonialismo e da colonialidade do poder, do saber e do ser. O termo "colonialismo" foi conceituado por Quijano (2009, p. 73) como uma "estrutura de dominação/exploração onde o controle da autoridade política, dos recursos de produção e do trabalho de uma população determinada domina outra de diferente identidade e cujas sedes centrais estão, além disso, localizadas noutra jurisdição territorial."

Conforme as elaborações teóricas dos pensadores do sul, as relações de colonialidade nos âmbitos econômico e político não foram interrompidas com o final do colonialismo, persistindo a contínua reprodução pelas culturas e estruturas capitalistas modernas/coloniais do sistema-mundo, por meio do controle da autoridade, da economia, da natureza e dos recursos naturais, do gênero e da sexualidade, da subjetividade e do conhecimento, ou seja, com a colonialidade do poder, do saber e do ser (BALLESTRIN, 2013).

Os europeus, segundo Lander (2005, p. 13), utilizaram as categorias eurocêntricas e organizaram o tempo e o espaço de todos os seres humanos, utilizando as particularidades culturais e históricas europeias como uma referência superior e universal para todos os povos. 
Dessa forma, não houve a consideração do conhecimento e da cultura de outras sociedades. Os modos de conhecimento e organização que não se enquadravam na visão única do colonizador eram tidos não somente como diferentes, mas como primitivos, arcaicos e inferiores.

A colonialidade ainda afeta a efetivação dos direitos na atualidade, conforme abordado, e destacam-se seus desdobramentos, especialmente, quanto ao direito ao acesso e uso da internet. Esse direito influencia diretamente na concretização do direito fundamental à educação, e as desigualdades sociais precisam de transformações consistentes e imediatas.

À luz de Silva T. (2017), pode-se inferir que o dia-a-dia do contexto escolar comumente são vistos como simples 'listas' de saberes, mas como parte constituinte de um complexo sistema de regulação, sobretudo em contextos marcados pela violência colonial. 'É no currículo que o nexo entre representação e poder realiza-se, efetiva-se. As imagens, as narrativas, as estórias, as categorias, as concepções, as culturas dos diferentes grupos sociais e sobre diferentes grupos sociais - estão representados no currículo de acordo com as relações de poder entre esses grupos sociais. (...) As representações são tanto o efeito, o produto e o resultado de relações de poder e identidades sociais quanto seus determinantes." (SILVA, T., 2017, p. 19).

É também no currículo que se condensam relações de poder que são cruciais para o processo de formação de subjetividades sociais. Em suma, currículo, poder e identidades sociais estão mutuamente implicados. O currículo corporifica relações sociais.

Nessa senda, Boaventura de Sousa Santos (2007) sinaliza a impossibilidade de coexistência entre o imperial e o colonizado e sintetiza pontos fundamentais para a compreensão desse fenômeno: o pensamento moderno ocidental como um pensamento abissal.

A divisão é tal que 'o outro lado da linha' desaparece enquanto realidade, torna-se inexistente, e é mesmo produzido como inexistente. Inexistência significa não existir sob qualquer forma de ser relevante ou compreensível. Tudo aquilo que é produzido como inexistente é excluído de forma radical (SANTOS, 2007).

Já o argentino Walter Mignolo (2017) sugere que a colonialidade é o lado obscuro da modernidade, responsável por instituir hierarquias em diferentes setores sociais, entre elas, para além da hierarquia epistêmica, também uma hierarquia estética, que administra os sentidos e molda as sensibilidades ao estabelecer as normas do belo e do sublime, do que é 
arte e do que não é, do que será incluído e do que será excluído, do que será premiado e do que será ignorado.

Mesmo com a formulação de uma pedagogia interétnica e promulgação de leis que condicionam o ensino de conhecimentos subalternizados, é possível notar que tais "respostas às inclinações opressivas e imperiais”, destacadas por Mignolo (2017, p. 3), apontam para o deslocamento das minorias da condição de objetos da representação para a condição de sujeitos que enunciam ou, nas palavras de Homi K. Bhabha (2007), indicam a passagem do cultural como objeto epistemológico à cultura como lugar enunciativo, promulgador, de modo que objetificados possam ser transformados em sujeitos da sua história e da sua experiência.

\section{CONCLUSÃO}

É preciso superar a colonialidade e obter mudanças para que crianças e adolescentes brasileiras tenham seus direitos efetivados. Assim, é urgente e necessário que as desigualdades sociais sejam reduzidas. É preciso respeitar as diferenças e a diversidade de culturas e étnico-raciais, valorizando toda a vida humana, seja do indígena, seja do negro, do pardo ou do branco, para que possam integrar a sociedade brasileira em condições de igualdade.

$\mathrm{O}$ acesso e uso da internet por crianças e adolescentes ficou premente em tempos de pandemia da Covid-19. Há necessidade de se ponderar entre o risco e os benefícios da utilização da internet pelas crianças. Dessa forma, é preciso realizar ações de proteção para os infantes por meio da família e também do Estado e de empresas.

Verifica-se que existe desigualdade no direito ao acesso à internet no Brasil. Os alunos que não têm computador e conexão de internet de boa qualidade ficam em condições inferiores àqueles que têm as condições adequadas para acompanhamento das aulas em tempos de pandemia.

A interdependência dos direitos faz com que a violação do direito do acesso à internet afete a efetivação de uma ampla gama de outros direitos fundamentais das pessoas, como o direito à educação, à vida, à privacidade, à segurança, à saúde, ao trabalho, à seguridade social, entre outros.

Tendo em vista essa correlação, se faz mister efetuar a garantia de todos os direitos e, especialmente nesse momento, enfoca-se a importância do direito ao acesso e uso da internet, 
pelos expressivos reflexos que emana para os demais direitos e, com mais premência na atualidade, o direito fundamental à educação.

\section{REFERÊNCIAS}

AGÊNCIA IBGE. Instituto Brasileiro de Geografia e Estatística. PNAD Contínua TIC 2018: Internet chega a 79,1\% dos domicílios do país. Rio de Janeiro: IBGE, 2020. Disponível em: https://agenciadenoticias.ibge.gov.br/agencia-sala-de- imprensa/2013-agencia-denoticias/releases/27515-pnad-continua-tic-2018-internet- chega-a-79-1-dosdomicilios-do-pais. Acesso em: 2 out. 2020.

ARIÈS, Philippe. História social da criança e da família. Trad. Dora Flaksman. 2. ed. Rio de Janeiro: Zahar, 1981.

BALLESTRIN, Luciana. América Latina e o giro decolonial. Revista Brasileira de Ciência Política, n. 11, p. 89-117, 2013.

BHABHA, Homi. O local da cultura. Belo Horizonte: UFMG, 2007.

BOURDIEU, Pierre; PASSERON, Jean Claude. A reprodução: elementos para uma teoria do sistema de ensino. Lisboa: Veja Universidade, 1975. Disponível em:

https://periodicos.fclar.unesp.br/rpge/article/view/13904/9901. Acesso em: 11 abr. 2020. BRASIL. Ministério da Educação. Programa alunos conectados. Brasília, 2021. Disponível em: https://www.gov.br/mec/pt-br/assuntos/noticias/projeto-alunos-conectados-e-prorrogadoate-dezembro-de-2021. Acesso em: abr. 2021.

BRASIL. Ministério das Comunicações. Rádio Educativa. Brasília, 2019. Disponível em: https://www.gov.br/pt-br/orgaos/ministerio-das-comunicacoes. Acesso em: abr. 2021. BRASIL. Secretaria Nacional dos Direitos da Criança e do Adolescente. Ministério da Mulher, da Família e dos Direitos Humanos. Fórum Nacional para a Proteção de Crianças e Adolescentes Vítimas de Exploração Sexual no Contexto de Pornografia na Internet. Brasília: MMFDH, 2020.

BROOKE, Nigel; SOARES, José Francisco (Org.). Pesquisa em eficácia escolar: origens e trajetórias. Belo Horizonte: UFMG, 2008.

CASTELLS, Manuel. A galáxia da Internet: reflexões sobre a Internet, os negócios e a sociedade. Trad. Maria Luiza X. de A. Borges. Rio de Janeiro: Jorge Zahar, 2001. 
CEC. Commission of the European Communities. Efficiency and equity in European education and training systems. Bruxelas: CEC, 2006. Disponível em:

http://ec.europa.eu/education/policies/2010/doc/comm481_en.pdf. Acesso em: 11 abr. 2021. CGI. Comitê Gestor da Internet no Brasil. Resumo Executivo: Pesquisa TIC Kids Online Brasil 2019. São Paulo: CGI.br, 2020. Disponível em: https://cetic.br/pt/pesquisa/kidsonline/publicacoes/. Acesso em: 9 nov. 2020.

DEMEUSE, Marc; BAYE, Adriane. Indicateurs d'équité educative: une analyse de la segrégation académique et sociale dans quelques pays européens. Revue Française de Pedagogie, p. 91-103, out./dez. 2008.

DUBET, François. Les dilemmes de la justice. In: DEROUET, Jean-Louis. C.; DEROUETBESSON, Marie-Claude. Repenser la justice dans le domaine de l'éducation et de la formation. Lyon: Peter Lang, 2009.

FAO. Organização das Nações Unidas para a Alimentação e a Agricultura. El estado de la inseguridad alimentaria en el mundo 2002. Roma: FAO, 2002. Disponível em: http://www.fao.org/3/y7352s/y7352s03.htm. Acesso em: 18 dez. 2020.

FAO. Organização das Nações Unidas para a Alimentação e a Agricultura. O estado da segurança alimentar e nutricional no mundo em 2019. Roma: FAO, 2019. Disponível em: http://www.fao.org/publications/card/en/c/CA5162EN. Acesso em: 12 dez. 2020. HERBAUT, Estelle. L'évaluation de l'équité scolaire: perspectives nationales et internationales. Education \& Formation, n. 80, p. 53-60, dez. 2011. Disponível em: http://media.education.gouv.fr/file/revue_80/29/8/Depp-EetF-2011-80-evaluation-equitescolaire-national-international_203298.pdf. Acesso em: 11 abr. 2021.

IBGE. Instituto Brasileiro de Geografia e Estatística. Dados e Estatísticas do Século XX. Rio de Janeiro: IBGE, 2000. (CD ROOM).

IBGE. Instituto Brasileiro de Geografia e Estatística. Desigualdades sociais por cor ou raça no Brasil. Rio de Janeiro: IBGE, 2019b. Disponível em:

https://biblioteca.ibge.gov.br/visualizacao/livros/liv101681_informativo.pdf. Acesso em: 20 set. 2020.

IBGE. Instituto Brasileiro de Geografia e Estatística. Pesquisa Nacional por Amostra de Domicílios Contínua - Educação 2019. Rio de Janeiro: IBGE, 2019a. Disponível em: https://biblioteca.ibge.gov.br/visualizacao/livros/liv101736_informativo.pdf. Acesso em: 09 fev. 2021. 
KASMIRSKI, Paula; GUSMÃO, Joana; RIBEIRO, Vanda. O Paic e a equidade nas escolas de ensino fundamental cearenses. Est. Aval. Educ., São Paulo, v. 28, n. 69, p. 1-25, set./dez. 2017. Disponível em: https://periodicos.fclar.unesp.br/rpge/article/view/13904/9901. Acesso em: 11 abr. 2021.

LANDER, Edgardo. Ciências sociais: saberes coloniais e eurocêntricos. In: LANDER, Edgardo. (Org.). A colonialidade do saber: etnocentrismo e ciências sociais - Perspectivas Latinoamericanas. Buenos Aires: Clacso, 2005.

LIMA, Silvia Peixoto de; RODRÍGUEZ, Margarita Victoria. Políticas educacionais e equidade: revendo conceitos. Contraponto, Itajaí, v. 8, n. 1, p. 53-69, jan./abr. 2008. LIVINGSTONE, Sonia; CARR, John; BYRNE, Jasmina. One in three: Internet Governance and Children's Rights. Global Commission on Internet Governance Paper Series, n. 22, 2015. MIGNOLO, Walter. Colonialidade: O lado mais escuro da modernidade. In: Revista Brasileira de Ciências Sociais, São Paulo, 2017.

ONU BRASIL. Nações Unidas Brasil. Crianças e jovens brasileiros são vítimas invisíveis das desigualdades no acesso a saneamento. Brasília: ONU Brasil, 2020. Disponível em: https://brasil.un.org/pt-br/88985-criancas-e-jovens-brasileiros- sao-vitimas-invisiveis-dasdesigualdades-no-acesso-saneamento. Acesso em: 30 nov. 2020.

ONU NEWS. Novo estudo revela mais 500 milhões de pessoas vivendo na pobreza no mundo. Brasília: ONU, 2019. Disponível em: https://news.un.org/pt/story/2019/07/1679661. Acesso em: 15 nov. 2020.

ONU. Declaração e Programa de Ação de Viena. Conferência Mundial sobre Direitos Humanos Viena, 14-25 de Junho de 1993. Viena: ONU, 1993. Disponível em: http://www.onumulheres.org.br/wp- content/uploads/2013/03/declaracao_viena.pdf. Acesso em: 27 dez. 2020.

PADILHA, Frederica et al. Qualidade e equidade no ensino fundamental público do Ceará. Cadernos Cenpec, São Paulo, v. 3, n. 1, p. 81-110, jun. 2013. Disponível em: http://cadernos.cenpec.org.br/cadernos/index.php/cadernos/article/view/215. Acesso em: 5 abr. 2020.

QUIJANO, Anibal. Colonialidade do poder e classificação social. In: SANTOS, B. S; MENESES, M. P. (Org.). Epistemologias do Sul. Coimbra: Almedina, 2009. p. 73- 118. RIBEIRO, Vanda Mendes. Que princípio de justiça para a Educação Básica? Cadernos de Pesquisa, São Paulo, v. 44, n. 154, p. 1094-1109, out./dez. 2014. 
SANTOS, Boaventura Souza. Para além do pensamento abissal: das linhas globais a uma ecologia de saberes. Revista Crítica de Ciências Sociais, n. 78, p. 3-46, out. 2007.

SILVA, Samara Renata Maciel. Inocência Perdida: Lilica riplica e o estímulo à adultização e erotização infantil. 2017. Trabalho de Conclusão de Curso (Graduação em Comunicação Social) - Universidade Estadual da Paraíba, Campina Grande, 2017.

SILVA, Tomaz Tadeu. Currículo e identidade social: territórios contestados. In: SILVA, Tomaz Tadeu (Ed.). Alienígenas na sala de aula: uma introdução aos estudos culturais na educação. Petrópolis: Vozes, 2017.

UNESCO. Crise da Covid-19: Unesco pede apoio ao compartilhamento de aprendizagem e conhecimento por meio de recursos educacionais abertos. Brasília: Unesco, 2020. Disponível em: https://pt.unesco.org/news/crise-da-covid-19-unesco- pede-apoio-aocompartilhamentoaprendizagem-e-conhecimento-meio. Acesso em: 2 dez. 2020.

UNICEF BRASIL. Convenção sobre os Direitos da Criança. Adotada pela Assembleia Geral da Organização das Nações Unidas (ONU) em 1989. Brasília: Unicef, 1989. Disponível em: https://www.unicef.org/brazil/convencao-sobre-os-direitos-da-crianca. Acesso em: 12 dez. 2020. 